\title{
Assessment of Elderly People Knowledge Regarding to Home Fall Prevention
}

\author{
Fatimah Hakami \\ Department of Nursing Education and Training, King Salman Hospital, Riyadh, KSA
}

\begin{abstract}
Background: Elderly falls are a major public health problem; home environmental hazards appear to pose the greatest risk for falls accidents among elderly people. Falls are defined in numerous ways; one commonly used definition is that of the "an event which results in a person coming to rest inadvertently on the ground or floor or other lower level".

Result: The Statistically significance correlation was found between socio demographic profile of the studied subjects related to elderly people knowledge' related to falls preventive measures.

Conclusion \& recommendations: it concluded that majority of elderly people more knowledgeable about home environmental hazards \& slightly less than half of them exposed to previous history of falls. Community nurse should be developing fall risk assessment/ screening tool, to assess all people above 55 years \& more for to identify those with high risk factors.
\end{abstract}

Keywords: Elderly people, home hazards, falls, knowledge, preventive measures.

DOI: $10.7176 / \mathrm{JHMN} / 67-03$

Publication date:October $31^{\text {st }} 2019$

\section{Introduction}

Worldwide, the fall prevalence rate estimated by 424000 fatal falls occur each year among elderly persons (WHO, 2016). According to CDC, 2016, mentioned that in the United States, every day an elderly people face falls accidents, making falls are the number one cause injuries and deaths from injury among Americans elderly.

Globally, falls are major public health problems, each year about one third of elderly aged 65 or older experience a fall, and each year elderly people are hospitalized for fall related injuries up to five times more often than other causes (WHO, 2007\& Sterling et al., 2001). Falls are not an inevitable part of aging. According to WHO (2013) define fall "as an event which results in a person coming to rest inadvertently on the ground or floor or other lower level". Home environmental hazards appear to pose the greatest risk for older people with unfair balance, whereas those with stable balance are less exposed to hazards and those with poor mobility are more able to falls accidents. The environment is perceived to play a significant role in many falls experienced by elderly people (Lord et al., 2006).

Saudis are becoming older and the percentage of the population over 60 was rising, and is expected to more than double by 2020 (CDS\&I,2009). However, little prior research has been undertaken examining elderly people falls in Saudi Arabia. Study done by Al Saif et al., 2012, results found that the three main factors that affect older persons' likelihood of falling are number of medications taken per day, sedentary lifestyle and use of assistive devices to help with ambulation. Thus, no single risk factor causes all falls, but the greater the number of risk factors to which an individual is exposed, the greater the probability of a fall. They recommended that efforts to reduce the risk from fall-related injuries should be directed at the development of a prevention program that identifies those at greatest risk due to factors such as age, medications and the use of assistive devices and the actions to modify these risk factors.

Community health Nurses has an essential role to reduce fall and its related injuries through educating the elderly people who are at high risk for falls or suffering from falls as a result from lacking knowledge about home hazards and safety measures. Safety measures include environmental modification, eliminating risk factors and improving the balance through exercise training program. Education must be directed toward helping elderly peoples to identify potential hazards and changing their health practice and habits accordingly (Danielsen et al., 2016). Another role was toward adequate physical, social and psychological rehabilitation of elderly people with a history of falls and injury to prevent further falls\& complications (El-Gilany e tal, 2013). The aim of This study was to assess elderly people knowledge regarding to home fall prevention of Riyadh city in Saudi Arabia. Significant associations and high rates of the elderly fall found between elderly fall and socio demographic profile. Demographic variable similar to social, spatial, and environmental factors, these variations may result to the elderly falls (Bamzar \& Ceccato, (2016).

\subsection{Literature reviews:}

In general, safety measurement at home has a significant effectiveness in reducing elderly people falls. However, all homes had at least one fall hazard. That mean ability to increase awareness through the development of plans and programs (CDC, 2016). Fall prevention involves managing elderly regarding to risk factors (e.g. Walking and 
transfer ring problems, psychoactive medication use, confusion, visual impairment, evidence of stroke or cancer, dizziness and frequent toileting) and optimizing the design of hospital equipment and the hospital environment (Chen, 2016).

Falls happen if the lighting is too dim or the surroundings are unfamiliar, also result from slipping on a throw rug that is not securely affixed to the floor. The second greatest number of injuries occur on stairs and steps, especially during descent. People commonly miscalculate the dimensions of the stair because of poor lighting in the stairwell or trip because of uneven stair heights or clutter on the steps (CDC, 2017). The fear of falling is very powerful and they may not even realize how this fear is limiting them daily activities (Verrall, 2013).

Studies (WHO,2016 \& Tromp et al., 2001), results showed that, eighty-eight percent of elderly people were able to identify falls as the most common cause of injury and $87 \%$ were able to accurately name at least one safety measure. At Canada, according to Division of Aging and Seniors Public Health Agency of Canada, 2015, stated that falls account for more than half of all injuries among Canadians 65 years and over.

Recent studies (CDC,2016), the results showed that most falls are the primary cause of injury-related deaths among elderly people, and many of these deaths occur after months after medical care and treatment. Globally, falls are major public health problems, it's the second leading cause of unintentional injury death, after road traffic injuries, also in all regions of the world. Death rates are highest among elderly over the age of 60 years (WHO, 2016).

Assessment of elderly people knowledge regarding home fall prevention consider to be an important issue because of homes environmental hazards which surrounding by most of the elderly people homes. Majority of the accidental falls are leading cause of injury-related death in elderly people. The most common hazards at home includes falls on stair and slips on bathroom, fires, burn, poisoning and choking (ching,2012).

Falls are destructive and common problems among elderly people, causing a massive amount of mortality and morbidity. Most of these falls are associated with one or more identifiable risk factors related that to a connection between biological, social and economic, environmental and behavioral risk factors (Rubenstein,2006). Biological factors, such as medical conditions among elderly people such as weakness, unsteady gait, confusion and certain medications. Environmental hazards, such as slippery floors \& lack of hand rails or grab bars. Smoking and poor practicing exercise are considerable behavioral factors (Scott et al., 2010 \& Rubenstein, 2006).

\section{The theoretical framework of this study}

The theoretical framework of this study was based on a theory developed by Nurse Ida Jean Orlando in 1958. The nursing process is goal-oriented method of caring that provides a framework to nursing care. It involves seven major steps: Assess, Diagnose, outcome identification, plan, Implement, Rational \& Evaluate, figure (1) (Alligood, 2014).

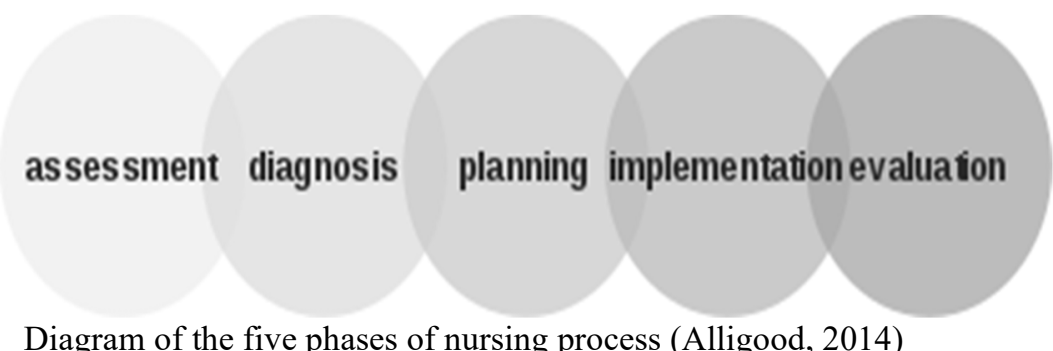

Diagram of the five phases of nursing process (Alligood, 2014)

The nurse completes a holistic nursing assessment toward elderly people knowledge regarding to home fall prevention. Assessment is the first step in the nursing process and includes collection, verification, organization, interpretation, and documentation of data. Optimal nursing care can help keep older adults on their feet and in their own homes. A comprehensive nursing assessment can minimize their risks for injury, hospitalization, or longterm-care placement (Black, 2014).

Fall risk assessment includes data obtaining a thorough health history (including chronic diseases, elimination patterns, and medications) and physical assessment, including mental status and gait and home evaluation, assessment (dry floor, bed rails \& lights, including night lights). After completing the home safety follow up with client-specific interventions to help older adults address modifiable risk factors and stay safe (Bloch et al., 2010, Rapp, 2009 \& Lord et al., 2008).

\section{Methodology}

This study design was a quantitative, exploratory cross sectional and correlation, conducted at King Salman Social Center - Riyadh, Kingdom of Saudi Arabia. The total study subjects were 302 elderly people age 55 years and more $(20.5 \%$ male and $79.5 \%$ female $)$ and Saudi nationality. 


\section{Results}

The elderly subjects were between 55 and more. Majority (72.5\%) of them were between age group (55-64 years). Majority (96.4\%) of them were live with their families. Majority $(83.8 \%)$ of them had enough income. About $45.0 \%$ of them had history related to falls. Majority $(75.7 \% \& 25.7 \%)$ of them mentioned the main causes of falls related to environmental \& medical causes respectively. About $69.1 \%$ of them had falls complications, $(28.7 \%$ \& $29.8 \%)$ from them had fractures \& contusion injuries respectively. Two thirds of elderly people had correctly identified most categories related to fall preventive measures at home. Statistically significance correlation was found between elderly people socio demographic profile \& their knowledge' related to falls preventive measures. except income not significant correlation found. The following table show the correlation between socio demographic profile of the studied subjects related to elderly people knowledge' related to falls preventive measures.

Table 1. The correlation between socio demographic profile of the studied subjects related to elderly people knowledge' related to falls preventive measures.

\begin{tabular}{|c|c|c|c|c|}
\hline \multirow[b]{2}{*}{ Socio- demographic variables } & \multicolumn{4}{|c|}{ Elderly people knowledge' related to falls preventive measurement } \\
\hline & & $\begin{array}{c}\text { Male } \\
(n=62)\end{array}$ & $\begin{array}{l}\text { Female } \\
(n=240)\end{array}$ & $\begin{array}{c}\text { Total } \\
(n=302)\end{array}$ \\
\hline \multirow[t]{2}{*}{ Age } & Chi-Square & 28.123 & 315.988 & 302.029 \\
\hline & p-value & $0.000^{*}$ & $0.000 *$ & $0.000 *$ \\
\hline \multirow{2}{*}{ Marital status } & Chi-Square & 123.052 & 145.927 & 132.113 \\
\hline & p- value & $0.000 *$ & $0.000^{*}$ & $0.000^{*}$ \\
\hline \multirow{2}{*}{ Education level } & Chi-Square & 123.158 & 300.223 & 122.895 \\
\hline & p- value & $0.000 *$ & $0.000 *$ & $0.000 *$ \\
\hline \multirow{2}{*}{ Job status } & Chi-Square & 86.032 & 284.354 & 96.997 \\
\hline & p-value & $0.000^{*}$ & $0.000 *$ & $0.000 *$ \\
\hline \multirow{2}{*}{ Residence } & Chi-Square & 12.128 & 15.134 & 27.603 \\
\hline & p- value & $0.002 *$ & $0.004 *$ & $0.000 *$ \\
\hline \multirow{2}{*}{ No of person } & Chi-Square & 315.258 & 27.942 & 320.116 \\
\hline & p- value & $0.000 *$ & $0.000 *$ & $0.000 *$ \\
\hline \multirow{2}{*}{ Income } & Chi-Square & 4.326 & 32.533 & 12.799 \\
\hline & p- value & 0.115 & $0.000 *$ & $0.002 *$ \\
\hline
\end{tabular}

*Correlation is significant at the 0.05 level

\section{Conclusion}

According to the findings of this study, it is obvious that slightly more than two thirds of elderly people had correctly identified most categories related to fall preventive measures at home. Statistically significance correlation was found between sociodemographic variables for elderly people and their knowledge toward home fall prevention. Elderly people in this study exposed to multiple factors which potentially risk falling accidents such as their environmental surrounding, medical conditions \& sleeping problems.

\section{References}

Al Saif, A., Waly, E\& Alsenany, S., (2012). The Prediction of Falls Among older people in Saudi Arabia. Journal of American Science, 2012; 8(6): 692-700.

Alligood, M. (2014). Nursing theorists and their work .8 th ed. St. Louis, MO: Mosby.

Bamzar, R., \& Ceccato, V., (2016). The regional ecology of elderly falls in Sweden. GeoJournal, 81(1), 23-36.

Black, B., (2014). Professional Nursing: Concepts and Challenges $7^{\text {th }}$, ed. St. Louis, MO: Saunders.

Bloch, F., Thibaud, M., Dugué,B. , \& et al. (2010). Episodes of falling among elderly people: a systematic review and meta-analysis of social and demographic pre-disposing characteristics. Clinics Sao Paulo 2010; 65:895903.

Centers for Disease Control and Prevention, (2016). home fall prevention questionnaire for older adults, National center for injury prevention and control, U.S.A.

Centers for Disease Control and Prevention, (2017). morbidity and mortality weekly reports, National center for injury prevention and control, U.S.A.

Central Department of Statistics and Information, (CDS\&I). (2009). Riyadh, Ministry of Health, K.S.A.

Chen, P., (2016). Elderly falls in hospitals. International Journal of Gerontology, 10(3), 125. doi: 10.1016/j.ijge.2016.06.001.

Ching, M., E., (2012). Unintentional Home Injury Risks Among the Elderly in Southern Nevada. http://digitalscholarship.unlv.edu/cgi/viewcontent.cgi? article $=2660 \&$ context $=$ thesesdissertations

Danielsen, A., Olofsen, H, \& Bremdal, B., (2016). Increasing fall risk awareness using wearables: A fall risk awareness Protocol. Journal of Biomedical Informatics (2016) ; 63:184-194. 
Division of Aging and Seniors Public Health Agency of Canada., (2015), The Safe Living Guide, A guide to home safety for seniors, Ottawa, on: Public Health Agency of Canada.

El-Gilany, A., Hatata, E., Soliman, S., \& Refaat, R. (2013). Prevention of recurrent falls in elderly: A pre-post intervention study in a rural community, egypt. International Journal of Collaborative Research on Internal Medicine \& Public Health, 5(4), 187-198.

Lord, S., Menz, H., \& Sherrington, C., (2006). Home environment risk factors for falls in older people and the efficacy of home modifications. Age and ageing, 35(suppl 2), ii55-ii59.

Lord, S., Sherrington, C., \& Menz, H. (2008). Falls in older people at home: risk factors and intervention strategies. Journal of the Human-Environment System, 11(1), 37-42.

Rapp, K.., (2009). Falls Prevention in Residential Care. Key note address, Residential Care Summit. Victoria B.C. 2009, 11: 5-6, 209

Rubenstein, L., (2006). Falls in older people: epidemiology, risk factors and strategies for prevention. Age and ageing, 35(suppl 2), ii37-ii41.

Scott, V., Higginson, A., Sum, A., \& Metcalfe, S. (2010). Falls and Related Injuries in Residential Care: A Framework and Toolkit for Prevention. Vancouver, BC: Centre of Excellence for Mobility, Fall Prevention and Injury in Aging, Centre for Hip Health and Mobility.

Sterling, D., O'Connor J\& Bonadies J., (2001). Geriatric falls: injury severity is high and disproportionate to mechanism. J. Trauma , (2001); 50:116-119.

Tromp,A., Pluijm, S., Smit,J., Deega, D., Boutera, L.,\& Lips p., (2001). Fall-risk screening test: a prospective study on predictors for falls in community dwelling elderly, J. Clin. Epidemiol. 54 (2001): 837-844.

Verrall, A., (2013), Aging and Physical Disability Rehabilitation Research and Training Center. Fall Prevention for Older Adults with a Physical Disability University of Washington.

World Health Organization,. (2013). Global Report on Falls Prevention in Older. Geneva (Switzerland): Aug. 8

World Health Organization,. (2013). Proposed Working Definition of an Older Person in Africa for the MDS Project: Definition of an older or elderly person. URL: http://www. who. int/healthinfo/survey/ageingdefnolder/en/[accessed 09.06. 15].

World Health Organization,. (2016). Global Report on Falls Prevention in Older Age., January 6th, 2016. 